\title{
CivilEng: A New International Open Access Journal in Civil Engineering
}

\author{
Angelo Luongo $+(\mathbb{D}$ \\ Department of Civil, Architectural and Environmental Engineering-DICEAA, University of L'Aquila, \\ 67100 L'Aquila, Italy; angelo.luongo@univaq.it \\ + Editor-in-Chief of CivilEng.
}

Received: 19 June 2020; Accepted: 19 June 2020; Published: 23 June 2020

Civil Engineering is the oldest branch of engineering. Since the dawn of civilization, man, moved by the need to find a shelter, tackled the problem of constructing a house. Then, to connect single houses, he built roads and bridges. Successively, while organizing cities according to primordial principles of urbanization, he invented aqueducts for cold and warm water, as well as thermal protections to improve his living comfort.

Civil Engineering developed together with the companion of Mechanical Engineering, joined by the same need to handle small objects (tools) to realize larger objects (artefacts or machines). Both tackled the problem by empirical approaches, which established rules as "best practices", handed down to following generations as correct and most effective.

In parallel to Civil and Mechanical Engineering, man developed purely abstract sciences. It seems that mathematics had initially no influence on engineering, although there exists a suggestive current of thought (Lucio Russo, “The Forgotten Revolution", Springer (2004), Italian Edition 1996) which affirms that the two disciplines met around the IV century B.C., reaching their maximum synergy with Archimedes (287-212 B.C.), before separating from each other after his death. The official version attributes instead to Galileo (1564-1642) and Newton (1643-1727), i.e., two thousand years later, the birth of the modern science, in which Mechanics, and consequently Civil Engineering, finally found solid theoretical foundations on which to grow. The general principles which today guide the activity of the civil engineer were formulated by giants of science, mainly mathematicians, such as Euler (1707-1783), Cauchy (1789-1857), Piola (1794-1850), De Saint Venant (1797-1886), Navier (1785-1836) and many others, all operating in the broad field of continuum mechanics.

Until a few decades ago, the research in Civil Engineering was characterized by the formulation of analytical models, useful for hand calculations, often tailored to specific problems, grounded on the general principles stated by the fathers of mechanics. Some examples include nonlinear elasticity, plasticity, buckling; seismic engineering, wind engineering, geotechnical engineering; dynamics, control, aero- and hydro-elasticity; fracture, fatigue, damage; masonry, steel and concrete mechanics, timber engineering; and multi-physical problems, such as saturated porous media, thermo-mechanics and piezo-electro-mechanics.

With the advent of informatics, however, which has exploded in the last few years, computation has taken over modeling. Researchers seem today to be no longer interested in formulating new theories, and supporting them by mathematical, though approximated, arguments; in contrast, they now completely rely on discrete numerical models, able to solve a large number of specific cases. Their point of view overturned the research methodology: no more a deductive (model-driven) approach, in which the application is a mere illustration of a general theory, but a (data-driven) inductive approach, in which the examples suggest the general principles.

The improper and immoderate use of the automatic calculus had the effect of decreasing the trust of the researcher (and the practitioner) in the model. The temptation to abandon it, since "reality is too 
complicated to be described by equations", is so great that nowadays, we observe the proliferation of rules, codes and best practices, which very often hide the mechanical origin (if any) that should have suggested them. Thus, one is led to believe that mechanics is no longer useful to Civil Engineering, and to argue that, since the theoretical research exhausted its task, it is preferable to collect ready-to-use solutions, in order to build a data bank. In general terms, rationalism has been substituted by empiricism; paradoxically, we come back to the pre-Galilean age, cancelling a few centuries of science or, better, substituting it with a new science.

The result of such a research trend is that, in the scientific world, Civil Engineering is perceived as an old and mature discipline, arrived at its terminus, in which it is not worth investing financial resources. As a matter of fact, worldwide grants are destined for the emerging (i.e., smart) branches of the sciences, and no funds are allocated to Civil Engineering, except perhaps the conservation of cultural heritage.

To invert such a dangerous trend, it is necessary to re-discover the roots of Civil Engineering, which are a mixture of: (i) rigorous theoretical principles, based on physics and mathematics, and (ii) technical solutions, experienced in several applications. We need to re-apply Galileo's teaching (never abandoned by physicists), which reconciles the observational and theoretical approaches, based on a continuous interaction between practice and modeling.

This new journal is an attempt to regain for Civil Engineering at least a part of the leading role it had in the scenario of the applied sciences. Good quality papers, which are not mere numerical applications of specific problems, but which deserve significant attention in the understanding of a phenomenon, are welcome. Purely numerical or experimental approaches are also accepted, provided they are accompanied by a strong speculative investigation, and finalized to extract a physical interpretation that is useful to enlarge the general knowledge of the problem.

All fields of civil engineering, which are based on rational models, are of interest to the journal. A non-exhaustive list of arguments follows.

- Solid mechanics: elasticity, plasticity, viscosity, damage, fracture, fatigue;

- Structural mechanics: modeling and design;

- Strengthening and retrofitting of existing structures;

- Mechanics of traditional and innovative materials;

- Structural dynamics and seismic engineering;

- Monitoring, active and passive control of civil constructions;

- Wind-structure, ground-structure and fluid-structure interactions;

- Geomechanics and geomaterials;

- Earthquake geotechnical engineering, soil stabilization;

- Hydraulics, hydraulic constructions; river, marine and coastal engineering;

- Environmental engineering: climate changes, ecosystems, renewable energy, recycling;

- Transport engineering;

- Topography and Geomatics;

- Building physics and sustainable materials;

- Modeling and urban planning, rural development;

- Decision, risk and failure analysis, disaster management

(C) 2020 by the author. Licensee MDPI, Basel, Switzerland. This article is an open access article distributed under the terms and conditions of the Creative Commons Attribution (CC BY) license (http://creativecommons.org/licenses/by/4.0/). 